\title{
Huntington disease-like 3
}

INSERM

\section{Source}

INSERM. (1999). Orphanet: an online rare disease and orphan drug data base.

Huntington disease-like 3. ORPHA:157946

Huntington disease-like 3 is a rare Hunting ton disease-like syndrome characterized by childhood-onset progressive neurologic deterioration with pyramidal and extrapyramidal abnormalities, chorea, dystonia, ataxia, gait instability, spasticity, seizures, mutism, and (on brain MRI) prog ressive frontal cortical atrophy and bilateral caudate atrophy. 